\title{
Study on the Strategy of Constructing Compliance Management System in Large State-owned Logistics Enterprises
}

\author{
Liu Zhongmin ${ }^{1}$ \\ ${ }^{1}$ School of Economics and Management, Shanghai Maritime University, 201306, China \\ Correspondence: Liu Zhongmin, School of Economics and Management, Shanghai Maritime University, 201306, \\ China.
}

Received: February 23, 2021

Accepted: March 30, 2021

Online Published: April 19, 2021

doi:10.5539/ibr.v14n5p49

URL: https://doi.org/10.5539/ibr.v14n5p49

\begin{abstract}
In order to promote the all-round compliance management in central enterprises, accelerate the management improvement in accordance with law, and strive to construct the central enterprises under the rule of law to ensure the sustainable and sound development, on November 2,2018, the SASAC issued the "Central Enterprise Compliance Management Guidelines((Trial), Subsequently, the local SASAC also issued relevant guidance documents, such as on December 28,2018, the Shanghai SASAC issued the "Shanghai SASAC Supervision Enterprise Compliance Management Guidelines (trial)". As for a large state-owned logistics enterprise, the daily operation and management involves various links and wide range, the establishment of compliance management system is particularly significant. This paper takes SASAC's guidelines as the criterion, carries out analysis on the previous management compliance and process control, the post-management risk identification and risk control, prevention and pre-warning, etc., combing the process and organizational structure of compliance management system construction, so as to build a complete compliance management system framework, and finally put forward effective recommendations and measures for compliance management in large state-owned enterprises.
\end{abstract}

Keywords: logistics enterprises, risk control, compliance management, risks

\section{Introduction}

Over the years, China's state-owned enterprises have made great progress in improving the system and innovating the system design, but it is not enough to embody the concept and principle of the rule of law. They are accustomed to the traditional management and thinking, and there is still a big gap with the modern concept and requirements of the rule of law. Strengthening compliance management is an inevitable requirement to realize the modernization of governance system and management ability to enhance comprehensive competitiveness. To achieve efficient management, we must vigorously promote the modernization and internationalization of corporate governance system and management and control ability for most and large-scale state-owned enterprises.

State owned enterprises are mainly distributed in the important industries and key fields related to national security and the lifeline of the national economy. They are the important pillars of the national economy especially the large state-owned logistics enterprises. Their operation activities affect many other types of enterprises and many aspects of people's lives, which undertake the important material transportation of the national economy and the people's livelihood. Therefore, the state-owned enterprises in China not only undertake important economic functions, but also undertake many social functions. With the development of economy and the change of macro situation domestic and abroad, the legal compliance risk faced by large state-owned enterprises in China is not only expanding in scope, but also deepening in degree. In particular, the litigation, arbitration cases and violation risk events caused by the lagging implementation of legal compliance prevention and supporting measures continue to exist at a high level, which has a huge impact on the performance of enterprises, reform and development, even survival and social welfare.

However, due to various reasons, some enterprises do not pay enough attention in the process of promoting legal compliance work in combination with their own actual situation. At the same time, at the specific work level, some ideas, layout, arrangements, measures and other aspects of compliance management are still unscientific or need to be improved. The reasons are as follows: first, there is no perfect enterprise compliance management 
framework; second, the authority of the compliance department of state-owned enterprises is weak; third, there is a lack of compliance management resources of state-owned enterprises.

Strengthening compliance management is an important embodiment of state-owned enterprises' political and rule-abiding, and it is also the requirement for state-owned enterprises to fulfill their social responsibilities. In particular, the state's increasingly strict supervision on ecological environment protection, safe production, resource development and utilization, market competition order, state-owned assets supervision, and major investment decisions puts forward new requirements and new challenges for state-owned enterprises' legal compliance management. The state-owned enterprises and their managers must comprehensively strengthen the compliance management, making use of the modern enterprise governance system to strengthen the management and control, and making decisions, implementing and supervising in accordance with the law.

The modernization of enterprise governance system and management and control ability is to make the enterprise governance system institutionalized, scientific, standardized and programmed, and to use the rule of law and enterprise system to govern enterprises. Most advanced enterprises use the principle of rule of law to scientifically allocate power and responsibility, and realize the coordinated operation of decision-making power, execution power and supervision power, thus forming a scientific governance system of modern enterprises. At the same time, the company insists that the internal system, standards and supervision of the enterprise are stricter than the external laws, regulations and supervision, formulating an advanced business management system, which strengthens the source compliance, process compliance, substantive compliance, continuously cultivates the internal compliance culture, and improves the management level of the enterprise itself.

\section{Journals Reviewed}

GMM method to test the 24 period data of 100 platforms shows that investors prefer the compliance platform, and the stronger the platform compliance is, the more investors will be attracted (Liu\&Xu\&Lei,2019) Regulator has shifted from deterrence-oriented law enforcement to compliance-oriented law enforcement ,and thus promoted co-regulation. However, how to respond to different compliance choices and promote the co-regulation between regulator-regulate still rely on the regulators to build the supportive institutions like risk communication, persuasion for obligation fulfillment and smart law education for the sake of legal dialogue and information sharing, and to reform one-way and rigid requirement in the application of regulatory tools like licenses and standards (Sun,2020, p123-133). In the era of big data, enterprises should give full play to the mechanism of big data audit to effectively assist enterprises in management decision-making. In view of the existing problems and reasons of the social responsibility compliance management of China's foreign investment enterprises, we can improve and perfect it from four aspects: comprehensively strengthening the risk awareness of social responsibility compliance, perfecting the system construction, integrating and implementing, optimizing the collaborative management mechanism with big data audit, and expanding the function space of big data audit(Tian\&Yuan,2020). The reasonable boundary of regulation and the motive of controlling the compliance behavior, and should further promote the governance structure as the center of the regulatory compliance to the governance mechanism as the core of the effective regulatory change in the regulatory content. Regulatory approach should rationalize the regulatory line, the prudential supervision and behavior supervision and separation, increase the proportion of non-mandatory governance guidelines, the implementation of negative list management strengthen corporate governance and regulatory compliance with other regulatory objectives, strengthen regulatory coordination, reduce compliance burden, and create a highly efficient regulatory environment(Li\&Li\&Hao,2020).The compliance risks of centralized procurement mainly rooted in demand risks, supply risks, financial operational risks and institutional risks. Various participants in the procurement process perceived compliance risks differently. Therefore, we should set up a risk communication mechanism and conduct comprehensive compliance control overall departments(Huang,2013).The criminal compliance system of state-owned enterprises not only promotes the reform of the unidirectionality criminal governance model, but also actively constructs a criminal compliance system that conforms to the theory of criminal charges from the perspective of diversified criminal compliance risks. Based on the effectiveness of supervision and implementation compliance considerations, the stratum classification theory of criminal compliance based on the three levels of state-owned enterprises, national laws and state-owned assets supervision undoubtedly becomes the legal basis for realizing the effective integration of corporate risk prevention and control and criminal compliance "stable and far-reaching" (Du\&Liu,2021).

The risk management role of board of directors in technology innovation, and disclosed that there are different effects from strategic risk control and internal operation risk control on technology innovation. This reflects the effectiveness of a board's risk supervision: its direct involvement in risk super vision versus its utilization of enterprise audit in risk supervision. The board's direct involvement in risk supervision moderates the positive 
effect of risk management on technology innovation. However, the use of enterprise audit in risk supervision plays a negative role on technology innovation. Technology innovation risk management of high-tech enterprises have important implications in emerging country or regions (Wu \& Jie, 2017).

It shows important significance of accelerating the development and application of regulatory technology in China in the current stage of tackling financial risks and continuously strengthening regulatory measures. Meanwhile, the current advantages of China's regulatory technology development and application and a series of constraints in the practice process. Finally, based on China's actual national conditions and the actual development of regulatory technology, related policy recommendations for further development and application of regulatory technology in the financial market are proposed (Xia\&Tang,2020).By constructing a correlation model containing a "risk-activity-event-control-case" structure, the cause and loss database is established for compliance and operational risk, and the risk transference along the risk chain is studied preliminarily. According to real world practice, a trinity system made up of theoretical re-search, IT systems and guarantee mechanisms is put forward. Years of practice has proved that this trinity system can serve as an important guidance for financial institutions to manage compliance and operational risk (Xiao \& Li \& Xu \& Chen, 2017).

Compliance management in the financial field is faced with dual privacy risk: one is the privacy risk that may arise from the business activities of financial entities; the other is the privacy risks that may arise from the compliance management itself. on the other hand is for financial entities of all business activities of the ethical countermeasures of privacy risks, special for shall have the right to contact and use of financial data, information of the clients ethical countermeasures of the compliance management personnel. In addition to the basic ethical countermeasures, in order to make the flexible ethical countermeasures not become a vase arrangement, it is necessary to safety guards corresponding institutional safeguards for them (Lv \& Paula, 2021).

From the domestic point of view, however, the main reason is lack of "good law and good governance" from the perspective of the rule of law. Specifically, the system is fragmented, with regard to a standardized system for cross-border data system, there is a lack of systemic design with a top down framework; the institutions are unclear, and an independent law enforcement institution for cross-border data risk management is absent; the regulatory methods are unclear, and the complete cross-border law enforcement process is absent. The countermeasures and suggestions for strengthening the rule of law under the guideline of "good law and good governance" to address the two-way compliance difficulties are: scientific law enactment, enrich and improve the value objectives or cross-border data flow management, and to provide a legal specification system for two-way compliance; innovatively reform institutions, establish an independent cross-border data regulator, and put two-way compliance into practice; collaborate to establish cross-border data security governance system, and create a favorable compliance environment; collaborate to achieve a win-win situation, actively participate in the formulation of international rules on cross-border data flow, and promote two-way healthy and sustainable compliance $(\mathrm{Xu}, 2020)$.

Compared with the significant increase in audit fee, the disclosure of significant defect in the internal control of listed companies has not caused any abnormal changes in the cost of corporate marketing cost, which means that the internal control of listed companies is more inclined to "regulatory demand" motivation. Disclosure of significant defect in internal control often leads to changes in executives, then changes in executives contribute to the remediation of corporate internal control defect, and the above mentioned result is more obvious in an environment where the government regulation is constantly strengthened. on one hand, our country's internal control construction has not truly become the enterprises' "self-discipline" behavior, and it still needs to strengthen external audit and internal control of government supervision, on the other hand, internal control defect disclosure institutional arrangements has an important pressure transferring value, which is conducive to the enterprise optimizing executive team, strengthening the internal control defect remediation and improving corporate governance (Lin \& Xu \& Wang, 2017).

The internal control defects will lead to an increased risk of corporate compliance, internal control defect repair can significantly improve the compliance management of enterprises and reduce compliance risk. Namely, as an "immune system" in a corporate, internal control can improve their immunity and make the immune system function better. Therefore, to detect defects in internal control and fix defects plays an important role in ensuring that the immune system of internal control continuously improve and realize the objective of system control (Lin $\& \mathrm{Li}, 2016)$.

The construction method of compliance from the perspective of corporation involves overall architectural and individual measures, particularly in risk identification, internal investigation and criminal risks in the fulfillment of compliance obligations. The significance of the compliance research from the perspective of corporation has 
two senses: providing useful reference for corporate compliance practice and helping judicial authorities probe scientific methods of condemnation and penalty measurement based on the effectiveness of compliance programs $(\mathrm{Li}, 2020)$. The key to achieve a higher level of corporate compliance still remains the advancement of internal voluntary compliance. The construction of China's compliance system is confronted with some particular issues brought by reforms like the New Normal as well as all the universal risk points. This process has made considerable achievements with many remarkable highlights. Meanwhile, based on the index evaluation of re-cent developments of China's corporate compliance, more challenges have been revealed by fluctuations of China's corporate compliance index curves. Considering the framework, focuses and the change of ideas and rules to integrate themselves into compliance without delay, instead of piecemeal improvements and institutional mending, it becomes particularly important for China's corporations to establish a more comprehensive compliance system gradually (Yang,2017).With big data and small data combined the latest trends of domestic and foreign business compliance research, discussed how to construct cognitively effective interface of Business Compliance, and then brought up a cognitively effective interface method that companies are more willing to comply with. This method changed the previous stereotype of hard intervention and strong intervention on business compliance, created a soft intervention and weak intervention pattern that fit business compliance selection preference better. Based on this method, a practical solution found which can achieve the perfect balance between profit making and compliance (Yang, 2020).

Clarifies the concept of enterprise compliance and two key parts of the compliance system: the control of compliance risk and the construction of compliance management framework; from the perspective of compliance risk control, extends the research focus to the field of export control compliance, and constructs the basic frame work of export control compliance management with reference to multinational compliance guidelines. Then, on the basis of summarizing the export control risks of Chinese enterprises, the paper puts forward the key points of export control compliance of Chinese enterprises' overseas operations and suggestions for improvement from the aspects of products, trading partners, employees, markets and record keeping(Han,2020).

The government companies mainly undertake CSR activities in response to the national and state governments' directions. This article advocates the inclusion of systematic and detailed procedures to increase accountability and transparency in companies' CSR activities. The establishment and an increased role of a specialized and independent regulatory watch-dog for auditing, monitoring and assessing the CSR activities of companies. By examining all the AAOIFI's GSs and focusing on the specific IBs' CG mechanisms. Furthermore, a major contribution of this study is the examination of the relationship between some SSB's characteristics and compliance level. To the best of the authors' knowledge, this is the first research that has examined the effect of the SSB's remuneration and expertise on compliance level (Yosra Mnif \& Marwa \& Tahari, 2021).

Government firms are found to make more proportionate overstatements compared to family and others (nonfamily and foreign companies). The fall in window dressing indicates that the companies' fabricating efforts in CG compliance are challenged by the regulatory change in a formal legal environment (Md \& Mahfuzur \& Shrabani, 2020).

The impact of corporate governance compliance and novel board attributes directors' attendance at board meetings, number of board committees, directors' remuneration and board foreign diversity on operating liquidity have examined. Further, it shows subdivides its sample period into pre and post corporate governance reforms to examine how external governance influences internal governance effectiveness (Javed\&Shafiq,2020).Some state-owned enterprises and private enterprises in China were included in the blacklist of the World Bank Group's official website and were sanctioned accordingly. To solve the dilemma faced by Chinese enterprises, the practitioners must understand the compliance requirements of the World Bank Group and act in accordance with its prescribed procedures. They must also establish an effective compliance system and system, and at the same time refine its system to ensure its implementation and conduct regular assessments and corrections. By conforming to the compliance rules formulated by the World Bank Group to lower the risk of sanctions, Chinese enterprises will establish an international image of integrity and compliance (Fang\&Fang, 2020). the implementation of a compliance programme (CP) in terms of how practitioners conceive of and execute the responsibilities arising from this corporate governance mechanism has investigated. A practice lens approach forms the case study analysis and interpretation, involving both interviews and documentary materials collected from an Italian company with prolonged compliance experience. The findings have theoretical and practical implications by revealing the relevance of practitioners' understanding of corporate governance mechanisms in their implementation processes. The potential benefits of practice lens approaches in corporate governance studies. It responds to the call for qualitative studies that demonstrate corporate governance as implemented in daily activities (Riccardo \&Francesca \& Silvano, 2020). 
Enterprises usually lack substantial motivation in establishing a compliance management system. In the future, how to ensure that enterprises implement effective compliance mechanisms without severe sanctions and establish a major incentive mechanism for corporate compliance in the areas of administrative supervision and criminal law will be a major issue to be addressed in China' s corporate compliance system (Chen, 2020).China's existed corporate compliance programs face many obstacles due to shortage or limitation of fundamental institutions. The paradox of China's corporate compliance program is revealed and reviewed, and need to be solved in expectation of transformation of existing legal fundamental institutions (Deng, 2020).

\section{Compliance Conceptions}

Compliance refers to comply with the regulations in apparent meaning. In recent years, the term "compliance" is oftentimes applied in the supervision and management of commercial banks in China. The Commercial Bank Compliance Risk Management Guidelines also clarify the meaning of compliance as follows:" it means that the business activities of commercial banks are in line with laws, rules and guidelines."

According to the definition of the new Basel Agreement, "compliance risk" refers to the risk that banks may be subject to legal sanctions or regulatory penalties, significant financial losses or loss of reputation for failing to comply with laws, regulations, rules, relevant standards set by self-regulatory organizations, codes of conduct applicable to banking businesses.

Serving as the requirement of the compliance relation of state-owned enterprises, the concept of compliance is clarified in the relevant guidance documents of the central and local SASAC. Compliance indicates that the business management of an enterprise and its employees conforms to the requirements of laws, regulations, industry codes and articles of association, company rules and regulations, as well as international treaties and rules. Compliance risk is the possibility that an enterprise and its employees may incur legal liability, be subject to related penalties, cause economic or reputational loss and other negative effects due to non-compliance. Compliance management means to effectively prevent and control compliance risks, with enterprises and employees' management as the object, carry out system formulation, risk identification, compliance review, risk response, accountability, assessment and evaluation, compliance training and other organized, planned management activities. Hence, the compliance management and system construction of a large state-owned enterprise should be based on the management and development of the enterprise and the behavior of the employees, and analyze from the internal and external, soft and hard fields, thus construct a comprehensive compliance management system that poses positive significance for the healthy and sustainable development of the enterprise.

\section{The Necessity of Compliance Management System Construction}

\subsection{Strengthen Compliance Management Is an Objective Requirement for Deepening the Reform of State-Owned Enterprises}

1) The reports of the 19th National Congress of the Communist Party of China explicitly pointed out that deepening the reform of state-owned enterprises, developing a mixed ownership economy, and first-class compliance management are the core competitiveness for enterprises.

2) The Guidance for Deepening the Reform of State-owned Enterprises of the CPC Central Committee (Central issuance [2015] No.22) puts forward that "enterprises should perfect the modern enterprise system, strengthen the internal supervision of enterprises, further give play to the role of legal advisers in legal supervision on enterprises operation and management, so that beef up enterprise management in accordance with the law and compliance". Therefore, strengthening compliance management is an consequent requirement to carry out the guidance of central enterprise supervision.

3) The state conduct more stringent supervision on state-owned enterprises

Opinions of the General Office of the State Council on the Establishment of a System of Accountability for Illegal Operation and Investment by State-owned Enterprises(General Office Doc No.63),SASAC promulgated the Measures on the Supervision and Administration of Central Enterprise Investment (SASAC Order No.34), the Law on Supervision and Administration of Foreign Investment of Central Enterprises (SASAC Order No.35), and the Notice on Strengthening the Control of PPP Business Risks of Central Enterprises (Doc No.192), the Notice of on the Regulation of the Project Library of the Integrated Information Platform for Cooperation between Government and Social Capital (PPP)(Doc No.92) by the Ministry of Finance, The state audit lays stress on the compliance of the procedure: "three majors and one focus" decision violation, heavy loss and waste, and so on; meanwhile, it pays attention to the effectiveness of internal control, weak internal control system and internal management, inadequate implementation of major resources utilization and environmental protection, 
potential threats in production safety; data authenticity; fraud in business and financial management.

4.2 Strengthen Compliance Management Is the Necessary Requirement of "State-owned Enterprises Ruled by Law" and the Strategy of Managing Enterprises According to Law in an All-Round Way

(1) The 19th CPC National Congress of the Communist Party of China put forward that "the overall law-based governance of the country is the essence and guarantee of socialism with Chinese characteristics". "Rule of law" and "according to law" were mentioned 67 times in this report, which fully integrates the spirit of rule of law.

(2) SASAC's "Opinions on Promoting the Comprehensive Construction of law-based Central Enterprises" proposed the new objective of building "state-owned enterprises ruled by law", and vigorously strengthened the construction of enterprise compliance management system. Huang Shuhe, former deputy director of SASAC, said at the 2014 working meeting on law-based central enterprises: "In the past decade, the experience and lessons of large enterprises at home and abroad have testified that the larger business show more dependence on the rule of law, in pursuing excellence, compliance is indispensable for enterprises." Therefore, compliance management is a new requirement to deepen the rule of law in enterprise, as well as a powerful tool to enhance the ability of managing enterprises according to law.

\subsection{Strengthen Compliance Management Is an Effectual Means to Implement Overall Party Self-Discipline and Incorruptible Business}

Intensifying compliance management is an effective mechanism to curb corruption. Compliance management can set up a "firewall" for enterprises, enterprise managers and employees in operation and business, so that keep them away from violations of regulations and discipline in work, thus ensure their integrity and incorruptibility.

\subsection{Compliance Management Is a Vital Management Means to Improve the Quality of Enterprise Management} and Boost Market Competitiveness.

\section{The Evolution of Compliance Management}

\subsection{The Compliance Management Development at Abroad}

The Overseas Anti-Corruption Act was enacted in 1977 and has undergone three amendments to prohibit United States enterprises and citizens, foreign enterprises listed in the United States or agents abroad from obtaining or retaining business to bribe foreign officials. The penalty may be reduced if the enterprise can demonstrate the existence of an effective compliance system, or if the enterprise voluntarily discloses, actively cooperates and pleads guilty.

In 2000, the United Nations issued the United Nations Global Compact, which called on enterprises to take into account the social welfare and the related social responsibility of economic activities in a manner that promises to comply with international standards of conduct. In 2004, it was were extended to ten fundamental principles of human rights, labor standards, environment and anti-corruption.

In 2004, the World Bank developed the blacklist system and the Integrity Compliance Guide, if an enterprise is sanctioned by a contracting bank, it will be barred for a period from participating in all projects financed by the contracting bank. The establishment and implementation of a compliance integrity system that meets the requirements is the major condition for conditional release of disqualification and early release of disqualification sanctions.

In 2010, the OECD enacted the 2010 Anti-Bribery Act, which combines bribery in the public and private spheres with comprehensive offences. In the meantime, a new crime was titled, "Business Organizations Negligence of Bribery Prevention", which stipulated the driving responsibility that commercial organizations should bear when they fail to construct internal bribery prevention system. In the same year, the development of the "Best Conduct Guide for Internal Control, Ethics and Compliance" requires enterprises to formulate clear policies to prohibit overseas bribery, establish compliance enforcement system for all employees, relevant communication and training mechanisms, and perfect reporting system.

In 2014, ISO developed the Compliance Management System Guide, which divides compliance management into two parts: establishment and improvement, including identification and regulation, establishment of compliance guidelines, assessment of compliance risks, development of response plans, implementation and control, assessment and reporting, and continuous improvement.

The 2016-1691 Act on Transparency, Anti-Corruption and Modernization of Economic Life was enacted in 2016. The Act stipulates that enterprises that meet the corresponding standards of employment and operating income should establish a compliance system and act as an obligation for enterprises and executives. 


\subsection{Compliance Management Development at Home}

December 25,2014, the State Capital Development Law [2014] No.193 of "Notice on Matters Related to the New Five-Year Plan for Promoting the Implementation of the Legal Work in Central Enterprises", which strives to deepen the construction of the legal risk prevention mechanism, legal advisory system and legal work system of enterprises through five years' efforts, further enhance the capability of compliance management and the capability to administer enterprises according to law, and "vigorously strengthen the construction of the enterprise compliance management system "as one of the key tasks.

On 8 December 2015, the SASAC issued [2015] No.166 "Opinions on Promoting Overall Construction of Law-based Central Enterprises", aiming to speed up the upgrading of compliance management capacity, establish a compliance management system led by the General Counsel of the Law, the legal affairs agency as the leading department, and the relevant departments to participate in and jointly manage compliance management system, study and formulate unified, effective, comprehensive and clear content compliance system guidelines, and strengthen compliance education and training, thus strive to form a benign mechanism for full compliance, so that explore the establishment of integrated management platform of law, compliance, risk, internal control.

On April 18,2016, SASAC issued regulations [2016] No.23 "Notice on Pilot Construction of Compliance Management System in Some Central Enterprises", in which SASAC selected five enterprises, including PetroChina, China Mobile, Dongfang Electric Group, China Merchants Bureau Group and China Railway, in order to carry out the pilot compliance management system construction.

On 23 May 2017, at the thirty-fifth meeting of the Central Leading Group for Comprehensive and Deepening Reform, "Opinions on Regulating Overseas Business Practices of Enterprises" was proposed, which called for the regulation of enterprises' overseas business practices, focusing on the construction of institutional mechanisms, highlighting problem-oriented practice, implementing corporate responsibilities, strictly enforcing discipline in accordance with the law, making up for the shortcomings of the system, strengthening the construction of compliance system for enterprises' overseas business practices, and gradually forming a regulatory system with clear powers and responsibilities, a combination of distribution and management, a standardized and orderly regulation, as well as a strong risk control system to better serve the overall situation of opening to the outside world.

On 1 July 2018 ISO19600GB/T 36770-2017 Compliance Management System Guide came into effect.

On 13 July 2018 SASAC implemented No.37 of "Measures for the Implementation of the Accountability for Illegal Operating and Investment in Central Enterprises (Trial)".

2 November 2018 SASAC issued [2018] No.106 Guidelines on Compliance Management of Central Enterprises (Trial).

26 December 2018 NDRC [2018] No.1916 Guidelines on Overseas Compliance Management of Enterprises.

28 December 2018 Shanghai SASAC (2018) No.464 Shanghai SASAC Guidelines on Compliance Management of Supervision Enterprises (Trial).

Compliance management and compliance operation of state-owned enterprises have become the leading trend and theme of the sound development of enterprises in China. 
Table 1. Comparation of Compliance Regulations

\begin{tabular}{|c|l|l|l|}
\hline $\begin{array}{c}\text { Comparison } \\
\text { Item }\end{array}$ & $\begin{array}{c}\text { Guidance on compliance } \\
\text { management systems }\end{array}$ & $\begin{array}{c}\text { Central Enterprise Compliance } \\
\text { Management Guidelines(Trial) }\end{array}$ & $\begin{array}{l}\text { Guidance on Compliance Management of } \\
\text { Overseas Enterprises }\end{array}$ \\
\hline $\begin{array}{c}\text { Issuance } \\
\text { institutions }\end{array}$ & $\begin{array}{l}\text { State Administration of } \\
\text { Quality Supervision, } \\
\text { Inspection and Quarantine, } \\
\text { China State Standardization } \\
\text { Administration Committe }\end{array}$ & SASAC & $\begin{array}{l}\text { National Development and Reform } \\
\text { Commission, Ministry of Foreign Affairs, } \\
\text { Ministry of Commerce, People's Bank of } \\
\text { China, SASAC, Foreign Exchange Bureau, } \\
\text { All-China Federation of Industry and } \\
\text { Commerce }\end{array}$ \\
\hline $\begin{array}{c}\text { Compliance } \\
\text { standards }\end{array}$ & $\begin{array}{l}\text { Compliance obligations is } \\
\text { compliance requirements } \\
\text { plus Compliance } \\
\text { commitments And outcomes }\end{array}$ & $\begin{array}{l}\text { Laws and regulations, regulatory } \\
\text { provisions, industry standards and } \\
\text { articles of association, rules and } \\
\text { regulations and international treaties } \\
\text { and regulations Possibility of being } \\
\text { penalized, causing financial or } \\
\text { reputational loss and negative } \\
\text { impact }\end{array}$ & $\begin{array}{l}\text { Requirements such as laws and regulations, } \\
\text { international treaties, regulatory provisions, } \\
\text { indandards, business practices, } \\
\text { and regulations formulated by enterprises } \\
\text { according to law Possibility of production } \\
\text { loss or reputation and other negative effects }\end{array}$ \\
\hline $\begin{array}{c}\text { Compliance } \\
\text { Management } \\
\text { focus }\end{array}$ & $\begin{array}{l}\text { Emphasize the importance of } \\
\text { compliance obligations }\end{array}$ & $\begin{array}{l}\text { seven fields and three links three } \\
\text { categories of personnel Overseas } \\
\text { investment and operation } \\
\text { Central enterprises as target other } \\
\text { enterprises implement by reference }\end{array}$ & $\begin{array}{l}\text { Focus on overseas business and standard } \\
\text { foreign trade, overseas investment and } \\
\text { foreign contracting projects }\end{array}$ \\
\hline
\end{tabular}

\section{The Construction of Compliance Management System}

\subsection{System Construction Principles}

The construction of a scientific and reasonable compliance management system provides great guiding significance for strengthening compliance management, especially for large state-owned logistics enterprise, a complete and targeted compliance management system poses positive impacts on strengthening internal management, improving management ability and reducing business risk.

Stick to risk-oriented principle; construct principle design compliance management system framework with the purpose of management institutionalization, system flow, sheet process, form informatization as the objectives.

Through on-site interviews, sample research, data analysis and other approaches to recognize the current situation of enterprise management system, sort out the potential risks faced by enterprises, and formulate effective risk control measures. Specifically, it could be concluded into "four through". That is, through the understanding of the current situation in enterprise management system, to clarify the responsibility and authority of each department, identify the demands of the enterprise's authority and responsibility setting, construct clearer responsibility and authority. Through the investigation of the present situation in enterprise management system, clarify the process of each business in the enterprise, understand the process setting requirements of the enterprise, and construct the legal standard and smooth operation flow. Through the communication of the demands in enterprise management system, sort and solidify various authorities and responsibilities, to extract the crucial risk points and countermeasures of internal control management in the hierarchical way, and form standardized system.

\subsection{Basic Framework for Compliance Management System}

The framework of compliance management system is expounded from the standard of laws and regulations to the scope of management, from management responsibility to management focus, from management operation to management guarantee. It is a standard version of the compliance management system formulated by state-owned enterprises, which is of high guidance value. In addition, it can be seen from this framework that the object of the compliance management system is mainly the enterprise business behavior and employees behavior. Otherwise, the implementation of compliance management will become a mere formality and fail to achieve the expected management objectives.

In accordance with the requirements of SASAC compliance management guidance document measures, the compliance management carries out normative management for enterprise operation and crucial employees, meanwhile, it explains the management responsibility in detail, management guarantee and management operation, especially the compliance management requirements of the key areas, key links and key personnel. 


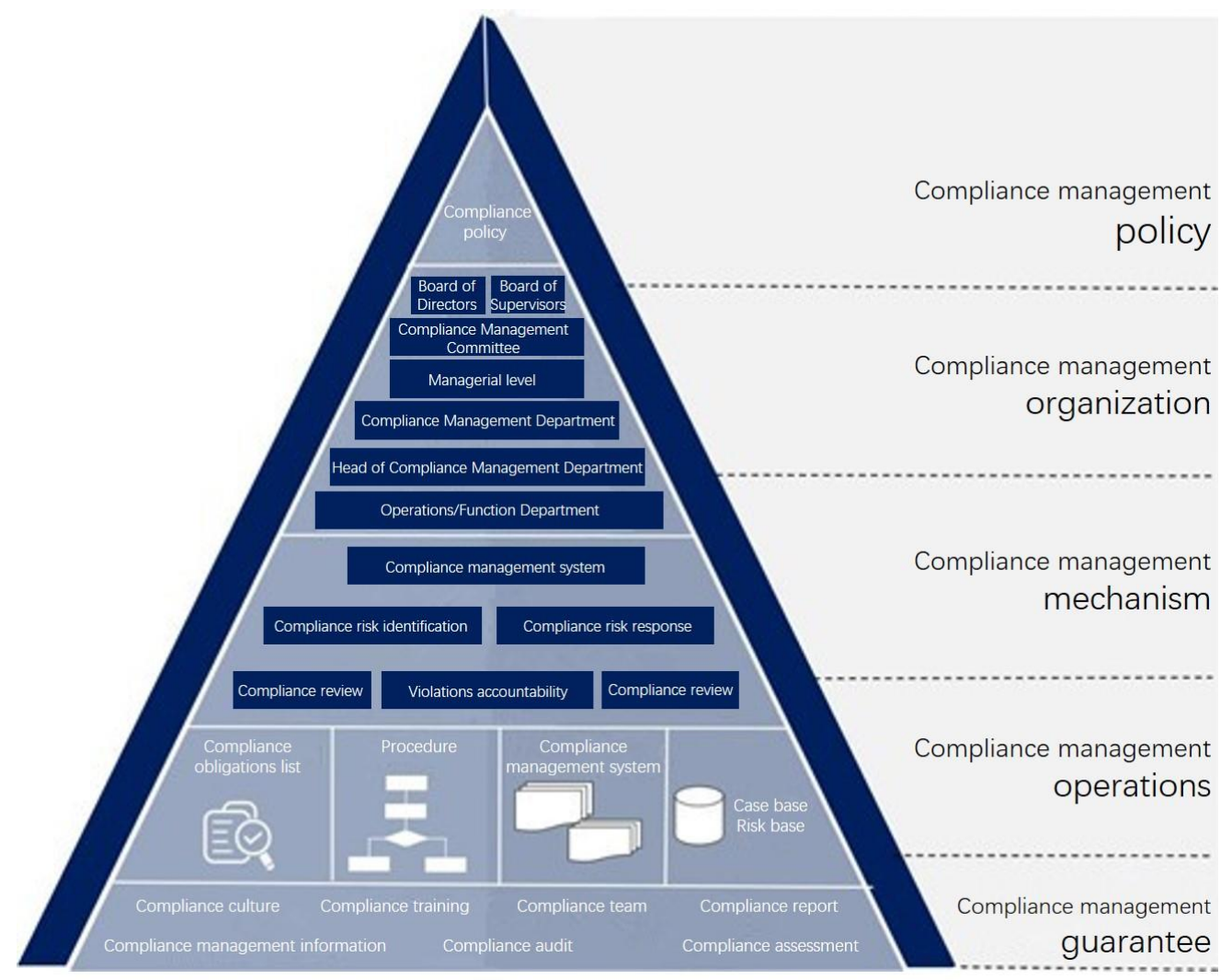

Figure 1. Basic framework for compliance management system

\subsection{Compliance Management System Framework of Large State-Owned Enterprises}

As to the construction of compliance management system of large state-owned logistics enterprises, it is imperative to formulate a compliance management system with industry characteristics based on the characteristics of logistics enterprises. According to the definition of compliance management, it is necessary to regulate the operation and employee behavior of the enterprise, in the meantime, the system guarantee, risk identification, risk control measures and training assessment mechanisms. Referring to SASAC compliance management system, it is supposed to fully consider the management responsibility, management focus, management guarantee and management operation of the compliance management system, while devise targeted management measures and risk prevention mechanism in combination with the characteristics of the industry.

In general, the operation and management of large state-owned enterprises bear the following characteristics. First, logistics enterprises operate a wide range of business, involving extensive geographical regions, such as the layout network all over the country, to facilitate the implementation of network business; Second, logistics enterprises are involved in more links, containing a variety of goods, sometimes of higher value, higher transport custody requirements and so forth; Third, the high-quality service provided by logistics enterprises is reflected in the smooth operation process, efficiency improvement and professional operation scheme; Fourth, the significant legal documents of logistics enterprises' external operation are agreements and bills, which are important materials to reflect the cooperative relationship and operation. Fifth, the state-owned logistics enterprises present more heavy assets in form, the assets management, safety and environmental protection call for strict management.

Furthermore, given the large state-owned logistics enterprise is the operation entity under the jurisdiction of SASAC, it requires to meet the requirements of the management of state-owned enterprises and the guidance requirements of the party-managed enterprises. Hence, in the design of compliance management system, the party discipline regulations and state-owned enterprises audit requirements shall be taken into account. Based on the above considerations, this paper designs a complete system framework for the compliance management in large state-owned enterprises. The design field includes prior management in the establishment of legal system, the compliance of enterprise operation, the behavior standard of employees, financial management and audit requirements, the process control of enterprise operation, etc., as well as post management, such as risk 
identification, risk control measures, prevention and early warning, thus become a complete and instructive compliance management system.

The enterprise compliance management information system is an indispensable tool to enable the enterprise compliance management system to be implemented on the ground. As an integral part of the enterprise management information system, the feasibility and effectiveness of embedding the compliance management information system into the existing enterprise management information system and platform through evaluation, so as to link up compliance management information system and other information systems of enterprise management for integrated coordination and shared exchange.

The enterprise compliance management information system is an indispensable tool to enable the enterprise compliance management system to be implemented on the ground. As an integral part of the enterprise management information system, the feasibility and effectiveness of embedding the compliance management information system into the existing enterprise management information system and platform through evaluation, so as to link up compliance management information system and other information systems of enterprise management for integrated coordination and shared exchange. By means of exploring the establishment of integrated management platform with law, compliance, risk, internal control, promote the coordination and linkage in compliance management and legal risk prevention, supervision, audit, internal control, risk management and other work, to guarantee the effective operation of compliance management system.

Table 2. Enterprise compliance management information system framework

\begin{tabular}{|l|}
\hline Compliance knowledge management \\
\hline Compliance organization \\
\hline Compliance risk management \\
\hline Compliance management system and processes \\
\hline Compliance review \\
\hline Compliance management evaluation \\
\hline Compliance management assessment and evaluation \\
\hline Compliance advocacy and training \\
\hline Violation management \\
\hline Compliance management plan and compliance reporting \\
\hline Compliance culture \\
\hline Constituent company compliance management \\
\hline
\end{tabular}

Table 3. Compliance management framework

\begin{tabular}{|c|c|}
\hline Prevention and pre-warning & $\begin{array}{l}\text { regulatory policy changes } \\
\text { risk alert mechanism } \\
\text { Maintain information symmetry } \\
\text { Compliance inspection review }\end{array}$ \\
\hline Laws and regulations abidance & $\begin{array}{l}\text { national laws and regulations } \\
\text { Industry codes and standards } \\
\text { Superior system requirements } \\
\text { enterprise decision-making mechanism } \\
\text { staff code of conduct }\end{array}$ \\
\hline Risk identification & $\begin{array}{l}\text { Business risk } \\
\text { Operation risk } \\
\text { Document risk } \\
\text { Safety and environmental risks } \\
\text { Employment risks } \\
\text { Financial risks } \\
\end{array}$ \\
\hline Operation compliance & $\begin{array}{l}\text { external business code of conduct } \\
\text { document regulation } \\
\text { standard operation } \\
\text { Efficient quality service standards }\end{array}$ \\
\hline System compilation & $\begin{array}{l}\text { Industry regulations } \\
\text { Decision-making system }\end{array}$ \\
\hline Financial management & $\begin{array}{l}\text { Budget management } \\
\text { Fund management } \\
\text { Asset management }\end{array}$ \\
\hline Process control & $\begin{array}{l}\text { Business process control } \\
\text { Production process control } \\
\text { Document control }\end{array}$ \\
\hline
\end{tabular}




\section{Implementation Path of Compliance Management}

\subsection{Compliance Management Process}

The framework of the compliance management system of large state-owned enterprises is designed above, it is followed by the organization and implementation of compliance management as an crucial link after the establishment of the system. How to effectively manage compliance throughout the daily business and employee code of conduct is the priority of compliance management. Prior to implementing and managing compliance, it is necessary to understand the occurrence trajectory of risk sources scientifically in order to formulate effective prevention and control measures. It can be seen from the following figure that the risk source first occurs in the detailed link of daily operation or the specific behavior of each employee. Once the risk event occurs, the loss caused by the event in the enterprise will be increasingly greater after the loss or failure of the risk event from the control department, supervision management and risk control mechanism. Meanwhile, it can also be found that the occurrence and spread of risk sources is gradually expanded without effective control and prevention. Therefore, the organization and implementation of compliance management, need the establishment of organizational structure, risk identification and prevention and control, compliance training and security and other aspects of comprehensive consideration, thus compliance management implementation path is targeted, control measures are oriented, and management objectives are projected.

\subsection{Establish a Compliance Management Department, Clarify the Responsibilities of All Parties}

In view of the characteristics of large state-owned logistics enterprises, such as wide management scope, many management outlets and complicated business, it is necessary to set up special departments to organize and implement daily compliance management, including constructing compliance management system, tracking and identifying compliance risk points, formulating prevention and control measures, and assisting in the development of compliance training scheme as well as reward and penalty mechanisms. Board of Directors responsibilities including as follows:

1) Review and approve the basic compliance management system, supervise the effective operation of compliance management system;

2) Decide on the establishment and responsibilities of compliance management bodies;

3) Review and approve the company's annual compliance management report;

4) Lead a compliance culture;

5) Other compliance management responsibilities as stipulated in laws and regulations and articles of association.

Managerial level responsibilities including as follows:

1) Organize the development of fundamental compliance management system and compliance manual;

2) Organize the formulation compliance management body setting programme;

3) Develop specific compliance management systems;

4) Audit annual compliance management report;

5) Organize the implementation of compliance management system, improve compliance management system to provide adequate conditions for legal advisers and risk control departments to perform their duties;

6) Maintain company compliance culture;

7) Other compliance management responsibilities under laws, regulations or articles of association

Compliance management responsibilities including as follows:

1) Responsible for the development and continuous updating of the company compliance management system and compliance manual, and promote its implementation;

2) Take charge of the comprehensive management of the company's rules and regulations, to ensure the company's rules and regulations legal compliance;

3) Identify, analyze, prevent and respond to compliance risks through compliance audits, compliance inspections, compliance risk alerts and reports;

4) Responsible for the compliance audit of the company's decision-making meeting proposals, rules and regulations, contracts, important economic activities, etc.

5) Foster a culture of compliance through the organization of compliance training, publicity and other 
activities;

6) Provide compliance advice and support to company management, compliance management and all employees;

7) Organize or participate in the compliance assessment, and cooperate with the audit department to organize the rectification on the internal control compliance evaluation related issues;

8) Assist the legal counsel organization to compile the company's annual compliance management;

9) Assist the legal counsel in organizing and coordinating compliance inspections;

10) Assist the discipline Inspection Commission to investigate and deal with violations;

11) Cooperate with HR department to build compliance management team.

12) Guide the company's affiliated units to establish compliance management system;

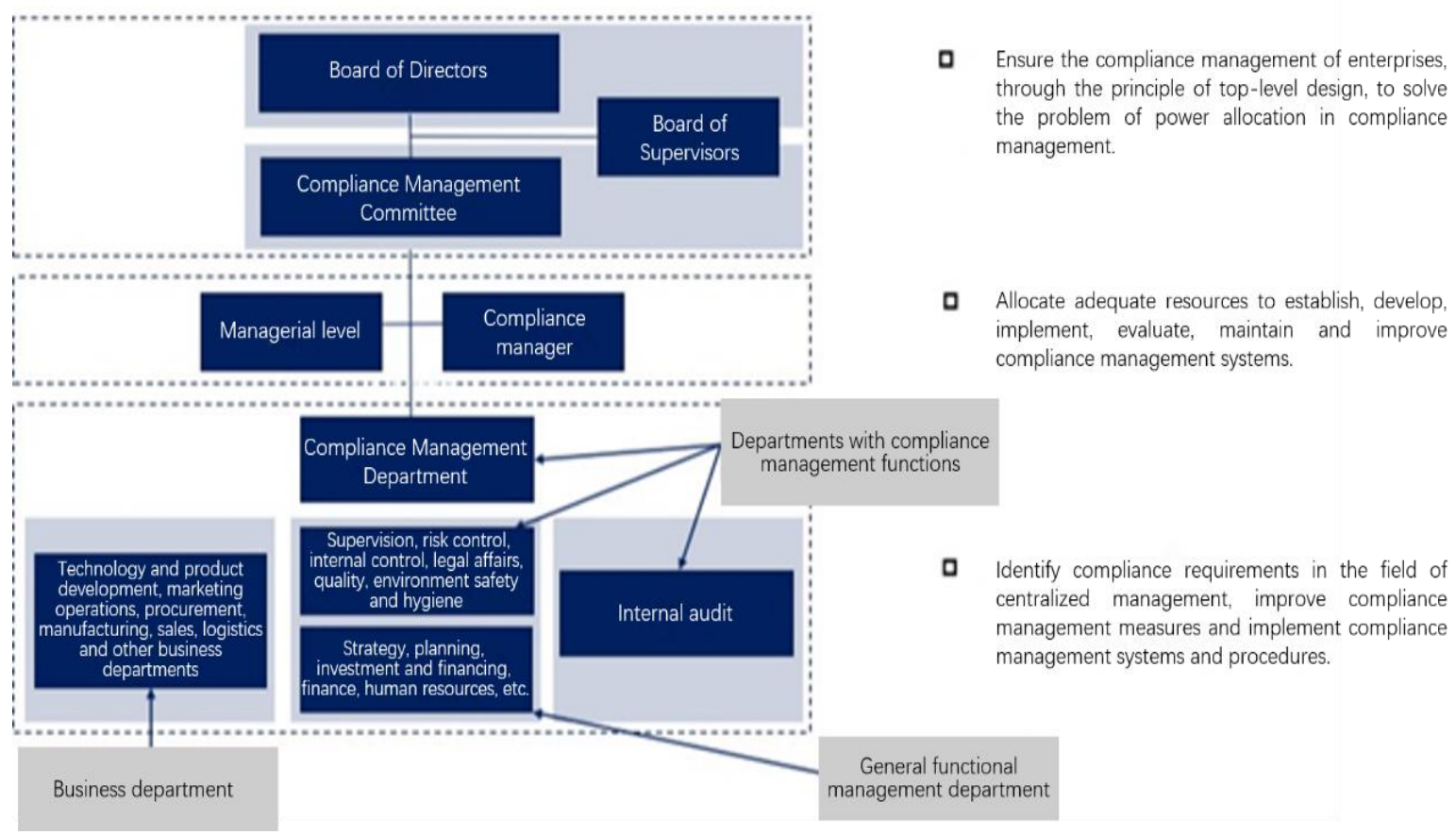

Figure 2. organization of compliance management department

\subsection{Develop Risk Identification and Wind Control Measures}

The management unit and the main body sorts out the inherent potential risk source, respectively combs, while the risk sources are identified and analyzed, and the risk sources are classified to raise the risk points with high risk level to the management objectives of the company level. For the medium risk sources, set up management objectives within the department or within the independent operating point. At the same time, for the above high and low risk sources, corresponding preventive measures and countermeasures shall be formulated to minimize the loss caused by potential risk sources.

Table 2. Risk Identification List

\begin{tabular}{|l|l|l|}
\hline $\begin{array}{l}\text { Non-compliance with national } \\
\text { legislation }\end{array}$ & $\begin{array}{l}\text { Non-compliance with enterprise } \\
\text { regulations }\end{array}$ & Non-compliance with morals ethics \\
\hline - Laws and regulations violation risks & - Information communication risks & - Commercial bribery risks \\
- Production safety risks & - Product technology risks & Market price manipulation risks \\
- Occupational health and safety risks & - Product quality risks & - Unethical fraud risks \\
- Environmental risks & - Product functional persistence risks & - Corruption risks \\
- Social responsibility risks & - Product technology patent risks & - Unresponsible product risks \\
- Social security risks & - Agreement default risks & - Malpractices risk \\
- Political risks & - Trade secrets risk & core corporate values violation risks \\
- Party discipline violation risks & - Asset preservation and appreciation & \\
& risks & \\
\hline
\end{tabular}




\subsection{Develop Compliance Management Safeguard Mechanism}

Compliance management requires the support of the safeguard mechanism, each employee's understanding of compliance is different, especially the key post personnel, regular organization of professional compliance training is particularly significant. Strengthen the overall staff compliance awareness and code of conduct, promote the transmission to the full scope of the enterprise. Establish compliance management reporting channels to form a time reporting mechanism for major compliance risks. Improve the assessment mechanism, refine the assessment objectives, and gradually form compliance assessment standards into the performance management system.

The inspection and control of internal audit becomes more crucial and timely in short of management department and compliance management department. As a state-owned enterprise, the party discipline regulation plays notable supervision function to the enterprise management behavior, including the daily prior party committee, three-level pre-control network and other measures, all of which safeguard the enterprise legal compliance management. Meanwhile, party discipline has established a regular restraint mechanism for the key posts and management personnel of state-owned enterprises, while guaranteeing the daily smooth operation of enterprises, protecting the key post personnel, and ringing the alarm bell for the compliance management of enterprises in ideology.

\section{Conclusions and Recommendations}

Compliance management has become a necessary work in the development of state-owned enterprises. If the role of compliance management can not be effectively played in the operation of enterprises, and lack of sufficient understanding of compliance management, it will affect the healthy and long-term development of state-owned enterprises. Therefore, the state-owned enterprises should strengthen the compliance management, and enhance the implementation of compliance management through effective compliance management strategies, so as to help enterprises effectively avoid risks and provide important power guarantee for the development of state-owned enterprises.

In the actual development process of state-owned enterprises, compliance should be regarded as the bottom line of enterprise operation and management. High attention should be paid to compliance management from the top management of enterprises, and all employees should be actively encouraged to participate in the compliance management of enterprises. Only in this way can we further enhance the development of compliance culture of state-owned enterprises, promote the effective improvement of management level of enterprises, and help state-owned enterprises to take the lead in the international market competition environment.

Large state-owned logistics enterprises need to strive in severe market competition, while comply with the requirements of enterprise control in the state-owned capital system, although it's incredibly hard in development and struggle for survival. Looking forward, logistics enterprises with high service standards and standardized management competence can have an edge in the market, thus achieve sustainable development in the long run. Hence, the establishment of sustainable compliance management system is a crucial measure for enterprises to release operational risks, enhance customer service quality and market competitiveness. The long-term mechanism of compliance management is manifested in compliance inspection, risk identification, prevention and control, compliance guarantee and training, etc. Only by running compliance management through the daily operation and employee behavior norms, the sound and stable development can be lasting. This paper has certain reference value and significance to the organization and implementation of compliance management in large state-owned logistics enterprises.

\section{References}

Chen, R. H. (2020). On the Sinicization of enterprise compliance. Science of Law. Journal of Northwest University of Political Science and Law, 34-48.

Deng, F. (2020). The Origin and Convergence of Corporate Compliance and Its Chinese Institutional Limitations. Journal of Comparative Law, 34-45.

Du, F. Z., \& Liu, Y. H. (2021). The Remodeling of Legal Theory for State-owned Enterprise Criminal Compliance System in China. Nanjing Journal of Social Sciences, 98-107, 119.

Fang, Z., \& Fang, X. R. (2020). An Exploration of China's Corporate Compliance in the World Bank Compliance System. Commercial Science Research, 27, 23-30.

Guidance on Compliance Management Systems (GB/T 357702017)

Guidelines on Compliance Management of Central Enterprises (Trial)(SASAC [2018]No.106)

Guidelines on Compliance Risk Management of Commercial Banks (CBRC [2006]No.76) 
Han, S. (2020). Analysis on the construction and key points of export control compliance of Chinese Enterprises. Public Management, 154-160.

Huang, S. (2013). Research on Compliance Risk of Centralized Procurement Management in Insurance Company. Insurance Studies, 119-127.

Javed, K., \& Shafiq, U. R. (2020). Impact of corporate governance compliance and board attributes on operating liquidity in pre-and post-corporate governance reforms. Corporate Governance, 20, 1329-1347. https://doi.org/10.1108/CG-04-2020-0156

Li, B. C. (2017). The Construction Method of Compliance Program from the Perspective of Enterprise. Law Science Magazine, 76-83.

Li, H. C., Li, W. A., \& Hao, C. (2015). Effect of Compliance on Governance Effectiveness in the Corporate Governance Supervision Environment -An Empirical Study Based on China Insurance Industry Data. China Industrial Economics, 98-113.

Lin, Z. G., \& Li, M. M. (2017). Internal Control Defects and Its Remediation on Compliance Risk:Research Based on "Immune System" Theory. Journal of Nanjing Audit University, 11-17.

Lin, Z. G., Xu, H., \& Wang, S. S. (2017). Internal Control Defect and Its Remediation, Compliance Costs and Executive Change. Journal of Hebei University of Economics and Business, 38, 89-98.

Liu, Y. J., Xu, J., \& Lei, Y. S. (2019). The impact of P2P platform compliance on selection of investors' platform. Finance Research, 21-15.

Lv, Y. H., \& Paula, A. A. (2021). On Privacy Issues and Ethical Countermeasures in Financial Compliance Management Under the Background of Big Data. The Theory and Practice of Finance and Economics, 42, 2-9.

Md Tariqul, I., Mahfuzur, R., \& Shrabani, S. (2020). Corporate governance reform and overstatement of compliance: Illustrations from an emerging economy. Business Strategy and Development, 3, 648-656. https://doi.org/10.1002/bsd2.129

Riccardo, S., Francesca, R., \& Silvano, C. (2020). Corporate governance in practice: the role of practitioners' understanding in implementing compliance programs. Accounting, Auditing \& Accountability Journal, 33, 887-911. https://doi.org/10.1108/AAAJ-08-2016-2685

Sun, J. J. (2020). From Regulatory Compliance Towards Co-regulation: the Case of Food Safety Regulation. Administrative Law Review, 123-133.

Tian, G. J., \&Yuan, Y. (2020). Social responsibility compliance management of foreign investment enterprises on big data audit condition. Finance and Accounting Monthly, 93-97.

Wu, Z. F., \& Jie, W. (2017). A research on the integration and supervision mechanism of technology innovation risks. Science Research Management, 38, 18-27.

Xia, S. Y., \& Tang, L. (2020). Research on the Theoretical Framework and Improvement Path of Reg Tech. Southwest Finance, 86-96.

Xiao, B. Q., Li, X. D., Xu, Y. Q., \& Chen, Y. Q. (2017). Process, compliance and operational risk management. Journal of management sciences in China, 20, 117-123.

$\mathrm{Xu}, \mathrm{D}$. Q. (2020). On the legal protection of cross border data flow regulation and two way compliance of enterprises. Oriental Law, 185-197.

Yang, L. (2017). Risk Points,Index Curves and Challenges of Corporate Compliance in China. Zheng Fa Lun Cong, 3-16.

Yang, L. (2020). How to Achieve the Perfect Balance between Profit Making and Compliance. Zheng Fa Lun Cong, 139-148.

Yosra, M., \& Marwa, T. (2020). The effect of Islamic banks' specific corporate governance mechanisms on compliance with AAOIFI governance standards. Journal of Islamic Accounting and Business Research, 21-43.

\section{Copyrights}

Copyright for this article is retained by the author(s), with first publication rights granted to the journal.

This is an open-access article distributed under the terms and conditions of the Creative Commons Attribution license (http://creativecommons.org/licenses/by/4.0/). 